\title{
El tiempo en La Celestina: el deseo, el placer y el egoísmo como motivos de interpretación de la obra
}

\author{
Diana Galarreta-Aima \\ Universidad de Virginia (UVA) Charlottesville, Virginia
}

\begin{abstract}
Each of the characters of La Celestina lives consciously with his own individual juncture of duration and dimension, of sentiments and argument, of experience and necessity.
\end{abstract}

Peter Russell, 146

El tiempo, en tanto dimensión dramática, ha sido un tema muy discutido por diversos críticos; algunos de los cuales consideran que la obra sufre de algunas "fallas» temporales ${ }^{1}$, mientras que otros, como Manuel J. Asencio, Stephen Gilman y María Rosa Lida de Malkiel², aseveran que Rojas maneja el tiempo de manera que se adecúa a los fines estéticos de la obra. Pues bien, funcional o no, en términos dramáticos, el tiempo, como

1.- El tema de mayor discusión se ha centrado en el cambio inverosímil de Melibea entre el primer capítulo, de completo rechazo, y los siguientes en los que expresa una desenfrenada pasión por Calisto.

2.- Manuel J. Asensio discute los supuestos errores temporales del texto de Rojas en el articulo «El tiempo en La Celestina» y Stephen Gilman en «El género y el tiempo literario en La Celestina» sostiene que existe una libertad artística en el uso del tiempo pues «los personajes hallan dentro de la obra una experiencia de tiempo más larga que el lector, quien, a causa de la forma dialogada, ha supuesto que estaba viviendo con ellos cada instante de la obra» (1945:150). María Rosa Lida de Malkiel también ha resaltado que el tratamiento del tiempo y el espacio sigue un principio de verosimilitud psicológica que permite la evolución del carácter de los personajes en la obra (180). Recientemente, Dorothy S. Severin, siguiendo los postulados de Lida de Malkiel (Originalidad, 179), señala que "Rojas does not maintain an uninterrupted time sequence, but includes in his acts a representative sampling of the interior development of the characters.» (43). 
categoría existencial, desempeña un papel fundamental en La Celestina. Todos los personajes tienen una clara y dolorosa conciencia temporal, y entablan una lucha entre la búsqueda inmediata de las satisfacciones de sus deseos personales y el paso irremediable del tiempo. El sentimiento del paso del tiempo y de la cercanía de la muerte, asevera Erna R. Berndt, "se resuelve en una ansiedad que se vuelca en una verdadera impaciencia vital» (98). El tiempo es vivido intensamente como una sombra de la cual los personajes no se pueden liberar y que los acecha constantemente como un perenne recordatorio de las limitaciones humanas: las agujas del reloj constriñen la libertad y el goce de los personajes. Por ello, las referencias temporales aparecen repetidamente, pero lo que diferencia el tratamiento del tiempo en La Celestina de otros textos del mismo periodo y que le confiere singularidad es que en la obra de Rojas este deja de ser un tópico literario, tempus fugit, para convertirse en una categoría existencial y efectiva en la vida concreta del hombre. Gilman ya ha destacado en The Art of Celestina que el tiempo en esta obra está en un permanente conflicto con el amor, pues aquel limita siempre la satisfacción de las pasiones humanas (132-140). Pues bien, me gustaría partir de esta postura y ampliar la dicotomía tiempo/amor a una oposición más general, ya que la influe cia del tiempo funciona como un determinante existencial que marca los distintos ámbitos de la vida de los personajes, es decir, el tiempo apremia a los amantes, pero también es un agente constrictivo de la vida como tal en sus distintas esferas. Así, todos los personajes entablan una contienda contra un enemigo al que saben, desde el comienzo, no pueden vencer, batalla que finalmente los arrastra hasta su destrucción. En el período de crisis en el que se inscribe la obra, esta pugna es, como señala el Prólogo del texto, una característica vital de hombre: «Todas las cosas ser criadas a manera de contienda o batalla» (77). Frente a este conflicto, a manera de escape, los personajes intentan manipular el tiempo, acelerándolo o dilatándolo, con el fin de disfrutar intensamente de los placeres que les ofrece la vida. Otros recursos empleados por los personajes, como veremos más adelante, son la imaginación, la memoria y el lenguaje. El objetivo de este trabajo es entonces analizar en detalle cada una de las batallas que entablan los personajes con este opresor implacable. Pero, además, si bien el tiempo empuja a los personajes al disfrute inmediato de la vida, también debemos considerar que son los mismos personajes los que construyen un tiempo personal, subjetivo; en otras palabras, el tiempo en La Celestina no es una categoría fija y unánime, sino que es fluctuante y personal. En este sentido, la propuesta de este artículo es realizar un análisis en dos direcciones, aparentemente opuestas, pero complementarias: por un lado, el tiempo como factor que constriñe las pasiones de los personajes y que, por tanto, mueve sus acciones, $y$, por otro, la creación de una conciencia íntima y relativa del tiempo de acuerdo a cada uno de los personajes. 
Celestina es claramente el personaje con una conciencia temporal más aguda porque percibe la concepción particular que cada personaje maneja de su propio tiempo, conocimiento empleado como herramienta para manipular los hilos del tiempo con el objetivo de obtener mayores beneficios económicos, aunque ello implique el sufrimiento de los otros. Como ha indicado José Antonio Maravall, el hombre de fines de la Edad Media sufre un proceso de individualización que, en La Celestina, se expresa a través del egoísmo y la avaricia. Por ello, esta "puta vieja», privilegiando intereses netamente individuales, expande y contrae el tiempo antes de complacer los deseos de los demás. Celestina sabe los diferentes matices que el tiempo puede adquirir para los amantes y es consciente de que la premura es una característica esencial que los identifica: «Si de noche caminan, nunca querrían que amaneciese; maldicen los gallos porque anuncian el día e el reloj porque da tan aprisa» (III, 144). Este conocimiento del funcionamiento de la psicología humana, que Celestina ha logrado a través de la experiencia, le permite manipular la pasión de los amantes prolongando o precipitando el tiempo antes de satisfacer sus apetitos. Este artilugio es evidente en el segundo encuentro de la alcahueta con Melibea. En un juego de pistas, palabras con doble sentido y sobreentendidos ${ }^{3}$, Celestina va avivando las ansias de Melibea para desvelar sus pasiones ocultas: "Quanto más dilatas la cura, tanto más me acrecientas e multiplicas la pena e pasión» (x, 241). La manipulación que emplea Celestina genera la desesperación de Melibea, quien llega a estar dispuesta a entregar la honra, valor tan preciado para la joven:

Melibea. ¡O cómo me muero con tu dilatar! Di, por Dios, lo que quisieres, haz lo que supieres, que no podrá ser tu remedio tan áspero, que yguale con mi pena e tormento. Agora toque en mi honrra, agora dañe mi fama, agora lastime mi cuerpo, avnque sea romper mis carnes para sacar mi dolorido coraçón, te doy mi fe ser segura e, si siento aliuio, bien galardonada. ( $\mathrm{x}, 242$ )

Como ya han señalado varios críticos (Lida de Malkiel 520, entre ellos), más que debido a la influencia de la magia, Celestina logra la rendición de los demás personajes por su gran capacidad retórica, que le otorga un gran poder de persuasión, y por su conocimiento de la psicología humana, especialmente de los procesos vinculados con los afectos y el deseo ${ }^{4}$.

3.- Estoy de acuerdo con Otis Handy, quien, en «La desfloración psicológica y retorica de Melibea», niega la supuesta candidez de Melibea ya que esta no es realmente seducida por Celestina, sino que participa en la aventura amorosa: «El dialogo entre Melibea y Celestina se podría entender como un combate retórico arbitrado por las apariencias» (384)

4.- Coincido completamente con la opinión de Ángel Alcalá sobre la significación de la magia en la obra: «Rojas presenta las oraciones de Calisto y los ritos plutónicos de la hechicera para granjearse la voluntad de Melibea en el mismo nivel mágico y supersticioso» (44). 
Estas poderosas armas le permiten exteriorizar los deseos ocultos de los demás, quienes se subyugan finalmente a su dominio. Su oficio es el engaño institucionalizado; su poder se cimenta en la rendición de los personajes, quienes le otorgan su propia libertad. Como sugiere acertadamente Mercedes Alcalá, todos conocen el negocio de la alcahueta y se liberan de los sentimientos de culpabilidad a través del desplazamiento de sus deseos hacia los artilugios de la puta vieja: "Celestina materializa a través de su discurso los deseos de los personajes, para ello necesita enunciar, pronunciar, sacar a la luz lo vedado, lo secreto, lo oculto» (47). La palabra, entonces, alimenta su dominio y le otorga el poder necesario para penetrar todas las esferas de la sociedad.

Una de las estrategias que emplea Celestina es el tópico del carpe diem, pues incita constantemente al goce inmediato de los placeres de la carne. Dorothy S. Severin ha estudiado cómo funcionan los procesos de la memoria en la obra y afirma que:
Celestina's consciousness lives in a distant past; the world of the present does not have the same impact on her, and she forgets recent occurrences. Yet she will use her memories of the past to influence Pármeno, Calisto, Melibea, Lucrecia. Sempronio, Pármeno, Calisto all live for the present or the future (49-50).

Sin embargo, lo original del uso de este tópico radica en que más que una sabia anciana que aconseja y advierte a los jóvenes sobre las consecuencias de la fugacidad de la vida o la inmediatez de las pasiones, Celestina, desde su propio aprendizaje mundano, invita al placer y, a través de este, ella logra un goce indirecto, imposible de otra manera a causa de su avanzada edad. Según Javier Herrero, "Celestina takes advantage of the young for her own sexual pleasure. By encouraging youthful characters to engage in sexual misconduct, she takes what should be her role - that of the elder who encourages moral purity - and perverts it» (32). Celestina goza a través del goce de los demás; ella usa el carpe diem no como una mera evocación retórica abstracta, sino como producto de su experiencia vital. En este sentido, Celestina emplea dos herramientas para lograr saciar los deseos: la memoria y la imaginación impulsada por estímulos sensoriales. De un lado, usa la memoria al traer hacia el presente recuerdos de su perdida y gloriosa juventud; de otro, emplea la imaginación a través de la experiencia ajena como mediación de un goce indirecto. Varias veces en la obra, Celestina rememora los placeres de su propia juventud, y frente a ese pasado dichoso, Celestina contrapone los achaques de su vejez y las marcas visibles que el tiempo ha infringido en su propio cuerpo. Así, frente a la imposibilidad de satisfacer directamente sus apetencias, la alcahueta sacia sus deseos a través de los otros. En este sentido, se puede observar otra de las modalidades de egoísmo de la 
que venimos hablando. Este placer mediado a través del goce ajeno está íntimamente vinculado con los sentidos de la vista, el oído y el tacto. La escena del primer encuentro sexual entre Areúsa y Pármeno es clave en este sentido. Rojas, a través de un cuadro muy erótico, retrata plásticamente el preámbulo sexual entre estos jóvenes: Celestina se deleita con el cuerpo de Areúsa en uno de los momentos de mayor erotismo del texto:

Celestina: ¡Bendígate Dios e señor Sanr Miguel, ángel! ¡E qué gorda e fresca que estás! ¡Qué pechos e qué gentileza! Por hermosa te tenía hasta agora, viendo lo que todos podían ver; pero agora te digo que no ay en la cibdad tres cuerpos tales como el tuyo, en quanto yo conozco. No paresce que hayas quinze años. ¡ $\bigcirc$, quién fuera hombre e tanta parte alcançara de ti para gozar tal vista! Por Dios, pecado ganas en no dar parte destas gracias a todos los que bien te quieren. Que no te las dio Dios para que pasasen en balde por la frescor de tu juuentud debaxo de seys dobles de paño e lienço. Cata que no seas auarienta de lo que poco te costó. No atesores tu gentileza. Pues es de su natura tan comunicable como el dinero. No seas el perro del ortolano. E pues tú no puedes de ti propia gozar, goze quien puede. Que no creas que en balde fueste criada. Que, cuando nasce ella, nasce él e, quando él, ella. Ninguna cosa ay criada al mundo superflua ni que con acordada razón no proueyesse della natura. Mira que es pecado fatigar e dar pena a los hombres, podiéndolos remediar. (VII, 202 el énfasis es mío)

Utilizando argumentos extraídos de la filosofía natural en boga, Celestina, guiada siempre por sus intereses personales, invita a Areúsa a cumplir los mandatos del orden propio de la vida vinculados con el goce de la carne y de la unión natural entre el varón y la mujer ${ }^{5}$. Luego de persuadir a la joven e invitar a Pármeno a la habitación, Celestina se complace en el placer ajeno: «No tengo ya enojo; pero dígotelo para adelante. Quedaos adiós, que voyme solo porque me hazés dentera con vuestro besar e retozar. Que avn el sabor en las enzías me quedó: no le perdí con las muelas» (VII, 208) ${ }^{6}$.Celestina cumple con esta unión un doble propósito: seducir a Pármeno para que se una a su proyecto contra Calisto y satisfacer sus de-

5.- Esperanza Gurza ha resaltado cómo Celestina usa su conocimiento sobre los impulsos velados de los personajes guiado hacia el placer inmediato de sus apetencias: «Celestina sabe, instintivamente, que el ser significa existir, vivir en el mundo, en un instante dado, cuya duración está fuera del humano control y que, por tanto, hay que aprovechar decididamente ese instante antes de que se vaya para siempre» (84).

6.- Como explica Geoffrey West, la relación entre imágenes vinculadas con las muelas y el deseo sexual es más antigua que el texto de la Tragicomedia. 
seos sexuales a través de la joven pareja. Ambas empresas están guiadas únicamente por intereses personales. Hay aquí un regodeo en el observar el placer ajeno. La escena es grotesca, pues esta anciana menciona varias veces que, a pesar de su vejez, aún siente deseos sexuales ${ }^{7}$. La escena del banquete entre las jóvenes parejas de criados en casa de Celestina ilustra también este placer mediado ${ }^{8}$. Nuevamente Celestina se deleita al observar cómo la juventud goza de los placeres de la vida:

Gozad vuestras frescas mocedades: que quien tiempo tiene e mejor le espera, tiempo viene que se arrepiente. Como yo hago agora por algunas horas que dejé perder cuando moza, cuando me preciaban, cuando me querían; que ya, mal pecado, caducado he; nadie, no, me quiere... ique sabe Dios mi buen deseo! Besaos e abrazaos, que a mi no me queda otra cosa sino gozarme de verlo. (Ix, 231-232, el énfasis es mío)

Si bien es obvio que esta escena tiene claras raíces literarias vinculadas con los placeres del banquete, lo original radica en el papel que desempeña Celestina como observadora voyerista del placer del otro. La complacencia en lo sensorial es de vital importancia en la comprensión del carácter de los personajes. Así, al placer de la comida y del vino, Celestina añade el deleite de la vista.

La memoria, la evocación del pasado, es otra herramienta que usa Celestina para corromper a Pármeno y persuadirlo sobre los beneficios de su empresa. Celestina subraya en momentos clave de la obra la verdadera identidad que el criado se esfuerza en ocultar. Retrayendo hechos del pasado, Celestina trae a la vida las andanzas de Claudina, maestra de la alcahueta y madre de Pármeno. Pero si este recuerdo genera beneficios para la anciana, también desencadena su propia muerte. Cuando Pármeno y Sempronio están en casa de Celestina para exigirle más beneficios económicos, la vieja nuevamente menciona a Claudina: «Y tú, Pármeno, no pienses que soy tu cativa por saber mis secretos y mi vida pasada y los casos que nos acontecieron a mí y a la desdichada de tu madre» (XII, 273). Si bien la codicia es el principal acicate del crimen de los criados, considero que el desencadenante final del asesinato en manos de Pármeno es la repulsa y el odio del criado frente a las rememoraciones de Celestina: "iNo me hinches las narizes con essas memorias; si no, embiarte he con nuevas a ella, donde mejor te puedas quexar!» (XII, 273). En los últimos segundos de vida que le quedan a Celestina, la vieja pide confesión. Es

7.- En la bienvenida a Pármeno y Sempronio al banquete, Celestina formula una broma que refleja su aún patente sexualidad: "¡Muchachas, muchachas! ¡Bobas andad acá bajo, presto, que están aquí dos hombres que me quieren forzar!» (IX, 224).

8.- Para un estudio más detallado de la escena del banquete véase el artículo de Eloísa Palafox, "Celestina y su retorica de seducción: comida, vino y amor en el texto de la Tragicomedia». 
claro que la obra se halla a medio camino entre la mentalidad medieval y la Edad Moderna. La presencia divina aparece únicamente como elemento secundario. La ausencia de la esperanza en un tiempo y espacio transcendentes es un elemento clave en la interpretación del texto. La vida de los personajes se desarrolla en la inmediatez del tiempo presente. De ahí que si bien los pedidos de confesión de Celestina y Calisto frente a una muerte inesperada subrayan aún los vestigios de una mentalidad cristiana medieval, no tienen la fuerza necesaria para pensar en un tono esperanzador en una mejor vida más allá de la existencia terrena. En este sentido, el suicidio de Melibea subraya justamente la preponderancia de la voluntad individual por encima del temor a Dios. Las muertes que se presentan en el texto, en un orden secuencial in crescendo, enfatizan la ausencia de la Providencia como soporte existencial: Celestina y Calisto recuerdan a Dios solo cuando están al filo de sus vidas, mientras que en el discurso elegíaco de Pleberio se destaca la omisión a cualquier referencia divina como medio de consuelo frente a la muerte.

Celestina, por otro lado, aprovecha la concepción hedónica del tiempo de los amantes. Gracias a su conocimiento de la psicología humana, va hilando y avivando los deseos de los habitantes de la ciudad. Este conocimiento le otorga un poder especial que le permite acceder a diferentes esferas y capas sociales. Su negocio se expande más allá de las zonas marginadas y penetra incluso la casas de los burgueses y nobles: "The incursion into Pleberio's physical space negotiated by Celestina and her confederates constitutes the disintegration of the illusionary walls of class and identity erected by Pleberio to keep the two worlds apart» (Gerli, 1997, 73). El negocio organizado de la hechicera y sus secuaces invade inclusive las instituciones religiosas. Celestina alardea sobre su dominio en toda la ciudad y su capacidad de conseguir mancebas al clero: «De media legua que me viesen dejaban las horas: uno a uno y dos a dos venían a donde yo estaba, a ver si mandaba algo, a preguntarme cada uno por la suya» (IX, 235). Como vemos, las horas espirituales (canónicas) son remplazadas por las humanas; el amor divino es substituido por el carnal. La subversión de los valores y reglas sociales, manejadas con gran astucia por la alcahueta, refleja claramente los nuevos valores que implicó el tránsito de la Edad Media a la Moderna. La Celestina encarna este turbulento cambio que afecta a todos los niveles de la pirámide social. Como sugiere Enrique Fernández, «el tiempo sagrado y ritual está empezando a dejar de ser significativo en los nuevos centros urbanos» (37). El tiempo comienza a tomar un cariz mucho más terrenal en el que las preocupaciones humanas tienen un rol primordial.

Además, existe en la obra una clara conciencia de aprovechar la oportunidad, como evento pasajero del se puede sacar mayor provecho, como una breve tregua que nos ofrece el tiempo y que, por tanto, no se puede dejar pasar. Según Berndt, «los personajes temen la posibilidad de perder 
la oportunidad de insertar la propia voluntad en el orden general» (168), y de ahí su encarnada lucha contra el inevitable sucederse de todo lo humano. Así, si bien algunos críticos han propuesto a la magia y sus infl jos como coadyuvantes de los propósitos de Celestina, es claro que ella solo aprovecha la coyuntura de las circunstancias y la complicidad de los otros. En este sentido, no son los poderes de la magia ${ }^{9}$ o la cándida torpeza de Alisa ${ }^{10}$ (Gilman 1972: 251) los que ocasionan el primer encuentro de Melibea con Celestina, sino que es claro que la madre de aquella colabora con esta ${ }^{11}$ al dar el consentimiento implícito de que su hija se reúna con la 'puta vieja' más conocida del pueblo: "[Y]a me voy recordando della. Una buena pieça; no me digas más. Algo me verná a pedir; di que suba.» (Iv, 152). Celestina solo saca provecho de la oportunidad que se le presenta: "agora es mi tiempo o nunca; no lo dejes» (IV, 153). Cuando ya la madre de Melibea se ha ido, Celestina solo explota el camino que la propia joven le abre. Mediante un diálogo plagado de dobles sentidos y entredichos, Melibea y Celestina ejecutan una performance, actuación que tendría como trasfondo un objetivo muy claro: la rendición de la joven a Calisto. Entonces, no solo Celestina aprovecha la oportunidad que Alisa le ofrece al dejarla sola con Melibea, sino que también esta se beneficia de la visita de Celestina como mediadora de su propia entrega a Calisto. Ambas pues obtienen beneficios de la oportunidad que les ofrece esta especial ocasión. Corinne Mencé-Caster ha estudiado la obra bajo las ideas agustinianas acerca de la responsabilidad humana guiada por el libre albedrío y la voluntad: "Pour Augustin, la doctrine de la responsabilité, tant qu'il n'y a pas de determination causale de nos actions. Aux yeux d'Augustin, ce qui fait la liberté et la responsabilité humaine, c'est la dependance de nos actions à l'égard de notre volonté» (226-7). De acuerdo con MencéCaster, es claro que la magia juega ante todo un rol decorativo; el predeterminismo que constriñe la acción de los personajes de la tragedia griega es remplazado por la iniciativa y libertad de los personajes, lo que confiere modernidad a La Celestina. Entonces, la rendición de Melibea se logra mediante una conjunción de causas y efectos en la que interviene la libre decisión de la joven empujada por las argucias de la alcahueta con el beneplácito implícito de su propia madre.

Los criados de Calisto, Pármeno y Sempronio, también tienen una particular conciencia temporal. Por un lado, Pármeno vive anclado a su pasado, el cual determina sus acciones presentes. Ansía huir de sus recuerdos infantiles y, por tanto, recurre a amagos desesperados por alejar a Celes-

9.- Véase el artículo de Peter Russell «La magia, tema integral de La Celestina».

10.- Joseph T. Snow analiza el personaje de Alisa como una figura trágica y cándida.

11.- Yolanda Iglesias estudia detalladamente la conducta imprudente de los padres de Melibea, cuyas acciones guiadas por el libre albedrio, determinan finalmente la muerte de su ser más preciado (59-64). 
tina de la casa de su amo con la excusa de cuidar de los intereses de este, cuando, realmente, solo vela por sus ambiciones personales. Como hemos visto, el desencadenante final del asesinato de Celestina es el rencor que experimenta Pármeno ante el recuerdo de sus oscuros antecedentes. Por otro lado, Sempronio es un sirviente mezquino, calculador y codicioso, sumergido en la inmediatez de su presente. La amistad que une a estos sirvientes se basa no solo en la coincidencia de clase social, sino también en el deseo por el disfrute inmediato de los placeres terrenales. Eros y Tanatos. Es decir, los amores con Areúsa y Elisa, y el asesinato de Celestina conforman los móviles de estos personajes. Además, a pesar de las diferentes perspectivas temporales de estos criados, es claro que ambos, luego de la rendición de Pármeno, son motivados por fuerzas egoístas, las cuales se expresan en sus deseos de aprovechar la coyuntura con el fin de adquirir su parte de la empresa contra su amo. Así, Pármeno, incitado por las palabras de Sempronio, se decide a ir a dar una sorpresiva visita a Celestina: "Que es una puta vieja; no le quiero dar tiempo en que fabrique alguna ruindad que nos escluya» (XII, 268). En su caso, esta premura por aprovechar la oportunidad genera su propia destrucción. A pesar de lo avanzado de la noche, los criados no están dispuestos a esperar al día siguiente y se dirigen presurosos a la casa de la alcahueta, donde los espera la muerte. Como ya he indicado, según Maravall, los criados están guiados también por el egoísmo y la avaricia. Y, puesto que Calisto no provee a sus sirvientes de los beneficios económicos suficie tes, estos buscan enriquecerse por ellos mismos (126). Al comienzo de la obra, Pármeno intenta disuadir a su amo de contratar los servicios de Celestina. Se comportamiento se rige de acuerdo a los valores típicos del servus fidelis. No obstante, Calisto, en vez de premiar su lealtad y buenos consejos, lo reprende; en vez de administrar correctamente su hacienda y cuidar del bienestar de sus criados, Calisto regala bienes a una alcahueta. $\mathrm{Ni}$ amo ni criados cumplen en La Celestina los papeles prototípicos de señor proveedor ni de sirvientes fieles. La sociedad en la que se inscribe el texto atraviesa un proceso de crisis; la estructura feudal está fracturada y esta transformación se revela en la clara conciencia de clase que tienen los personajes y en las relaciones conflictivas entre los distintos estratos sociales. Así, la avidez de Pármeno y Sempronio por gozar de los mismos placeres que su amo, en el campo amoroso como material, genera sentimientos de envidia y rencor, los cuales los empujan al crimen, el cual conlleva su muerte.

Por otro lado, para Calisto, quien encarna las exageraciones pasionales del amante cortés, el amor es vivido como una experiencia atormentante, dolor agudizado por las adversidades del tiempo, el cual es siempre sentido como un enemigo personal. Ello determina la cambiante conciencia subjetiva con que Calisto vive su(s) propio(s) tiempo(s). Por ello, durante los momentos de separación entre él y Melibea, el tiempo es vivido co- 
mo un lapso muy prolongado, y durante los encuentros pasionales, es experimentado como un período brevísimo ${ }^{12}$. En el primer caso, Calisto quiere que las horas del día corran a mayor velocidad para que llegue la noche y con ella los deleites del sexo " $\mathrm{O}$ Oh luziente Febo, date priessa a tu acostumbrado camino! ¡Oh deleytosas estrellas, apareceos ante de la continua orden! ...Pues vosotros, inuernales meses, que agora estáys escondidos jviniéssedes con vuestras muy complidas noches a trocarlas por estos prolixos días!» (II, 128). En La Celestina, la prisa es una característica constante de todos los personajes en esta obra. Julio Rodríguez-Puertolas indica acertadamente que estos «aparecen dominados por la prisa e impaciencia de vivir, y lo que es más importante, vivir intensamente, como si proveyesen el cercano y trágico final» (236). Por ello, la exaltada pasión de Calisto genera tensión dramática, pues la premura de sus deseos hace que el normal paso del tiempo se torne insoportable (Lida de Malkiel 360). En este sentido, Gilman [1945] y María Embeita han señalado que, además de una dimensión netamente física, existe en La Celestina una conciencia temporal subjetiva, la cual genera la impresión de un tiempo psicológico muy breve o prolongado según el estado anímico de los personajes. Por ello, las horas previas al encuentro con Melibea son vividas por Calisto como una eternidad que inútilmente quiere acortar; sin embargo, es consciente de que esta aspiración es vana pues el orden cósmico regido por el tiempo es inamovible (Lida de Malkiel 363) ${ }^{13}$. A comienzos del acto XII, Calisto interroga a sus sirvientes por la hora exacta: «qqué hora da el relox?» (255). El tiempo es medido por un instrumento mecánico que simboliza la imperturbabilidad del mundo frente a los deseos humanos ${ }^{14}$. Además, la medición del tiempo en La Celestina, como indica Enrique Fernández, retrata el mundo de las nuevas ciudades. La precisión horaria que se logra con la introducción de los relojes mecánicos, que van sustituyendo las intuiciones basadas en la observación de los astros, incita una mayor conciencia sobre la inexorabilidad del correr de las horas (32-33). En esta medida, Calisto representa una faceta del hombre medieval consciente de su pequeñez y de sus limitaciones ante fuerzas que están más allá de la voluntad humana. Por otro lado, Calisto, más que gozar del momento del deleite en sí, experimenta un 'goce' anticipado en

12.- En el acto XIV, Calisto se queja del breve tiempo que ha estado con su amada, duración vista a partir de su psique interna: $\bigcirc \mathrm{O}$ breve deleyte mundano, cómo duran poco y cuestan mucho tus dulçores» (288).

13.- Véase también el artículo de James F. Burke «Sympathy and Antipathy in La Celestina» para una explicación más detallada sobre la cosmovisión medieval sobre el orden universal.

14.- Como señala Berndt, el tiempo cronológico «permanece indiferente a las pasiones humanas, tiene su ritmo inmutable y sigue su curso fatal» (161). Con respecto a la preocupación por los relojes en la obra, Russell señala que "there is probably no cast of characters in western literature which is more aware, not of Time as the mournful accomplice of Death and Fortune, but of the particular time of the day or night» (137). 
la espera y un placer posterior en el recuerdo de los momentos de placer. Calisto usa pues, al igual que Celestina, la imaginación, la memoria y el lenguaje como armas de defensa ante un enemigo tan poderoso como es el tiempo (Lida de Malkiel 358). Asimismo, al igual que esta, Calisto no experimenta el placer directamente sino que su deseo está mediado por las palabras. Calisto se complace en sus propios discursos; se autoerotiza con sus propias creaciones discursivas. Esto explica la extraña melancolía que experimenta Calisto luego de su encuentro sexual con Melibea: «¿Por qué no estoy contento?» (XIV, 291). Entonces, a modo de autodefensa, Calisto recurre nuevamente a la imaginación como fuente de placer: «Pero tú, dulce imaginación, tú que puedes, me acorre. Trae a mi fantasía la presencia angélica de aquella imagen luciente, vuelve a mis oídos el suave son de sus palabras, aquellos desvíos sin gana...» (xIv, 292). Los encuentros con Melibea son para Calisto solo un pretexto para alimentar sus fantasías; usa a Melibea, o su sustituto, el cordón, como simples objetos que excitan su verdadera fuente de placer: sus propios pensamientos y creaciones discursivas.

Pero, por otro lado, Calisto también simboliza un aspecto importante del hombre renacentista, faceta vinculada con su extremo egoísmo. Este lo ciega de tal manera que, luego de la muerte de Pármeno y Sempronio, Calisto está más preocupado por satisfacer sus apetitos sexuales que cuidar del buen nombre de su hacienda y vengar la muerte de sus sirvientes, egoísmo que finalmente desencadena su propia muerte:
Mañana haré que vengo de fuera, si pudiere vengar estas muertes; si no, pagaré mi inocencia con mi fingida ab- sencia o me fingiré loco, por mejor gozar deste sabroso deleyte de mis amores, como hizo aquel gran capitán Ulixes por euitar la batalla troyana e holgar con Penélope su mujer (XIV, 282).

De ahí que su muerte sea presentada bajo una luz irónica. En el único momento que Calisto muestra intereses por el otro, la seguridad de sus criados, sufre una caída, literal y simbólica, que ocasiona su muerte.

Melibea es un personaje a quien injustamente se le ha negado complejidad y ha sido estudiada como un carácter unidimensional en tanto mera amada pasiva sin iniciativa de acción. Sin embargo, es evidente que ya el primer autor de la obra quiso dotar a este personaje de mayor complejidad y agudeza que a Calisto, quien es incapaz, por ejemplo, de comprender el comentario sarcástico de esta en su primer encuentro: «Pues, jaun más ygual galardón te daré yo, si perseveras! (I, 87). En el detallado análisis que María Rosa Lida realiza acerca de los personajes de esta obra, se destaca el carácter activo de Melibea inclinado hacia la acción inmediata y práctica por oposición al «ensimismamiento melancólico» de Calisto (410). Rojas mantuvo y delineó las características que el primer autor im- 
primió en Melibea, quien también tiene una particular noción del tiempo. Recordemos que en el primer encuentro entre esta y Celestina, se produce un choque de dos visiones disímiles del tiempo. En esta escena, es evidente que en La Celestina no existe una concepción de un tiempo único y universal, pues esta noción ha sido remplazada por una perspectiva subjetiva y relativa. Así, Melibea no puede identificar quién es Celestina pues han pasado dos largos años desde la última vez que la vio: "No es tan poco tiempo dos años, y más que la tiene arrugada» (IV, 158). Sin embargo, este mismo lapso, vivido por la joven como un período prolongado, probablemente por los diferentes cambios físicos y emocionales vinculados con esta edad, supone una extensión menor para la alcahueta. Cada persona configura, por tanto, una estructura temporal subjetiva que depende de la particular situación de los personajes.

Otra escena en la cual también somos testigos del carácter subjetivo y, por tanto, relativo del tiempo es la despedida de Areúsa y Pármeno luego de su primer encuentro sexual. Con gran maestría, Rojas parodia y desacraliza la tradicional escena de despedida entre los amantes al amanecer. Nuevamente se produce aquí el encuentro de dos formas de experimentar el tiempo. Para la ex prostituta, las horas no han pasado pues el placer ha recortado el lapso al lado del amante: "¿Qué amanescer? Duerme, señor, que aun agora nos acostamos» (VIII, 211). En cambio, Pármeno se halla angustiado por la posible tardanza que puede notar su amo y de las represalias de las que podría ser víctima. Sin embargo, y a pesar de que estas perspectivas difieran, el tiempo psicológico de ambos personajes está determinado por sus ávidos deseos de búsqueda de sus ambiciones personales. Areúsa vive un «tiempo recortado» porque el goce sexual ha generado un olvido temporal momentáneo mientras que Pármeno intensifica su preocupación por las horas debido al temor al castigo, el cual podría desencadenar además un recorte de beneficios por parte de su amo.

Por otro lado, Rojas dota de complejidad interior a sus personajes cuando los presenta ante una disyuntiva en la que deben asumir una determinada posición. Muchos de ellos atraviesan un proceso de deliberación antes de decidirse por un determinado camino. Nosotros, como testigos de estas contiendas personales, sentimos cómo el tiempo es un elemento constante que apremia a los personajes a asumir una decisión y sus posibles riesgos. En estas contiendas personales, el cinismo y el egoísmo han remplazado a la moral cristiana medieval, orientada por preocupaciones ultraterranas. Los personajes de La Celestina eligen, luego de un proceso de deliberación en el que Dios y la moral se hallan ausentes, la opción que más beneficios augure. Así, el primer debate de la obra no es el de los protagonistas, Calisto y Melibea, sino de uno de los personajes marginales, pero de mayor complejidad, Sempronio. Este se debate entre entrar o no al cuarto de su amo. Finalmente, luego de balancear las posibles ventajas que podría obtener, se decide a entrar, pero no lo guía un sentimiento de 
solidaridad o fidelidad, sino que su resolución se basa en la sospecha de que puede sacar provecho de la pasión desbordante de su amo y en su odio velado contra este.

Lucrecia, por su parte, también tiene dos alternativas: advertir a su ama de los peligros que supone su relación con Celestina o abandonarla a los perniciosos propósitos de la vieja. La doncella elige esta última opción, probablemente debido a su secreta animadversión contra Melibea y por el goce indirecto en la observación de los encuentros sexuales de los amantes, además por el vínculo de parentesco que une a Lucrecia con Elicia. Otro de los personajes que atraviesa un proceso interior antes de asumir un riesgo es Celestina. Antes de seducir a Melibea, balancea las posibles ventajas y desventajas; finalmente, asume el riesgo de la opción que le puede dar mayores beneficios: «Pues, triste yo: mal acá: mal aculla: pena en ambas partes: quando a los estremos falta el medio: arrimarse el hombre al más sano es discreción. Mas quiero offender a Pleberio que enojar a Calisto» (III, 150). Pero, además de la avaricia, la elección de Celestina también está determinada por su orgullo de infalible alcahueta. Ambos vicios, la arrogancia y la codicia, reflejan el fuerte individualismo que mueve las acciones de la vieja. Pármeno, antes de unirse al proyecto contra su amo, también atraviesa un proceso de auto deliberación. Nuevamente, la decisión que asume el personaje se basa en su fuerte individualismo: movido por la codicia y el deseo sexual, Pármeno rápidamente abandona la inicial fidelidad hacia su amo. Según María Ebeita, la transformación del criado es significativamente lenta, pues, antes de aceptar la propuesta de Celestina, Pármeno atraviesa una serie de oscilaciones y regresiones (128). Considero, sin embargo, que la adhesión a su amo oculta las verdaderas razones de su aversión a Celestina: su supuesta lealtad solo es una máscara para encubrir la verdadera motivación que explica el rechazo contra Celestina, pues este tiene como verdadero motor disimular sus orígenes, los cuales suponen un impedimento para la aspiración de Pármeno de lograr una mejor posición social. Entonces, bajo la fingida preocupación por el bienestar de Calisto, Pármeno oculta una intención más egoísta, nueva muestra del individualismo que caracteriza a los personajes de la obra. Asimismo, Centurio, a pesar de ser quizá el personaje más estereotipado de la obra, también pasa por un proceso de deliberación antes de asumir una decisión que proteja sus intereses personales y al mismo tiempo satisfaga los pedidos de Areúsa. Por ello, luego que esta se retira, el rufián se pregunta: "¿qué consejo tomaré, que cumpla con mi seguridad e su demanda? (XVIII, 317). Como vemos, la decisión de Centurio está orientada para salvaguardar su vida y alimentar su orgullo; en otras palabras, el propulsor de sus acciones es también el egoísmo. Por su parte, Melibea, ante la coyuntura entre el amor filial o la pasión, elige la opción fatídica del suicidio, guiada exclusivamente por principios egoístas. Es consciente del dolor que su decisión generará en su padre, pero ya 
ha probado los deleites del amor y no está dispuesta a renunciar a ellos. Su prisa por alcanzar al amante más allá de la muerte precipita su propia destrucción. Sin embargo, más que pesar por la muerte del amante, Melibea experimenta dolor porque sabe que esta supone el fin de sus deleites. Cuando se entera de la muerte desastrosa de Calisto, Melibea solo se lamenta de la pérdida de su propia alegría y placer; nuevamente es claro que el egoísmo prima en las reacciones de los personajes. Es curioso que en su lamento Melibea no mencione el nombre de su amante y que más bien prime el yo como centro de su discurso:

¡Oh desconsolada de mi? ¿Qué es esto? ¿Qué puede ser tan áspero acontecimiento como oigo? Ayúdame a subir, Lucrecia, por estas paredes. Veré mi dolor; si no, hundiré con alaridos la casa de mi padre. jMi bien e placer, todo es ido en humo! ¡Mi alegría es perdida! ¡Consumióse mi gloria! (XIX, 327; el énfasis es mío).

Como se puede observar, la muerte aparece en la obra, hecho destacado por Maravall, como una figura que limita el placer terrenal (119). Se ha abandonado la preocupación medieval de pretender una buena vida en la tierra para gozar de una mejor más allá de la muerte. En La Celestina, el disfrute solo se piensa en términos terrenales y de ahí la visión pesimista de la muerte. Elicia es otro de los personajes que también experimenta una contienda interior. Entre demostrar su pena por la muerte de su protectora y de su amante, y continuar su vida licenciosa, Elicia prefiere concluir con su corto luto: "Quiero pues deponer el luto, dejar tristeza, despedir las lágrimas que tan aparejadas han estado a salir» (XVII, 307). Nuevamente este es un personaje arrastrado por su avaricia. Sabe que el luto puede alejar a sus clientes, y decide despojarse rápidamente de él. En La Celestina el amor como sentimiento trascendente está completamente ausente; el deseo carnal salvaje y el egoísmo son las únicas motivaciones que impulsan a los personajes. Por ello, Elicia abandona tan prontamente su luto pues más que dolor por la muerte de sus amantes, ella y Areúsa usan estas muertes como pretexto para satisfacer un deseo de venganza y envidia contra Calisto y, especialmente, contra Melibea. Nuevamente es evidente que el odio y la envidia median las relaciones entre los sirvientes y sus amos.

El miedo es otro factor que desencadena la preocupación por el tiempo. Los cobardes criados de Calisto, Pármeno y Sempronio, muestran su impaciencia durante los encuentros entre su amo y Melibea, y no dudan en abandonarlo en el caso de un posible peligro. El retrato cómico que presenta Rojas de estos sirvientes enfatiza claramente su cobardía. Pármeno, por temor a un posible castigo, rehúsa a cumplir la orden de Calisto de entrar en la casa de Melibea. El sirviente usa el lenguaje como medio de persuasión para engañar a su amo y modo de autojustificación para excusar su cobardía: 


\begin{abstract}
"¿Yo, señor? Nunca Dios mande que sea en dañar lo que no concerté; mejor será que tu presencia sea su primer encuentro, porque viéndome a mí no se turbe de ver que de tantos es sabido lo que tan ocultamente quería hazer e con tanto temor faze o porque quiçá pensará que la burlaste» (XII, 257).
\end{abstract}

Pármeno también utiliza los principios de la filosofía natural para justificar su brutal egoísmo: "Huygamos la muerte, que somos moços. Que no querer morir ni matar no es couardía, sino buen natural» (XII, 263). Sempronio y Pármeno están únicamente interesados en salvar su propia vida y no demuestran ninguna preocupación por los riesgos que puede correr su amo. Las palabras de Sempronio descubren su velado odio a Calisto: «En sintiendo bullicio, el buen huyr nos ha de valer. Déxale hazer, que si mal hiziere, él lo pagará» (XII, 263). En La Celestina, como acertadamente ha subrayado Maravall, «los criados apetecen la riqueza, anhelan bienestar y felicidad, son dados al amor y no encuentran fundamento para que el goce de estos y otros bienes esté reservado a los poderosos» (110). Por tanto, la base del cruel pragmatismo e individualismo de los criados se explicaría por el período de crisis de la sociedad señorial del siglo XV en el cual la orientación hacia la preocupación por salvaguardar los propios intereses marca la mentalidad de la época.

El miedo de Melibea también es otro factor que genera una preocupación por el tiempo y el consecuente interés por sacar mayor provecho de este. Uno de los argumentos que emplea Celestina para persuadir a la joven se basa en los estragos que el tiempo infringe en el cuerpo. Celestina representa para la joven un espejo futuro que refleja las terribles secuelas que el tiempo, en apenas dos años, puede ocasionar. En su diálogo, según Javier Herrero, «the old woman is darkening her own image to make Melibea especially aware of the charms of her own youth, and move her to enjoy her senses while they are in full bloom» (38). Luego de una larga enumeración de los achaques de la vejez, Celestina atemoriza a Melibea sobre el imperceptible paso del tiempo y el irremediable cambio de todas las cosas con el objetivo de incitar el disfrute momentáneo que le permite su juventud: "Señora, ten tú el tiempo que no ande, tendré yo mi fortuna que no se mude. ¿No has leído, que dicen: vendrá el día que en el espejo no te conoscerás?» (IV, 158). Mediante esta técnica de reflejos, Celestina persigue dos propósitos: incitar la entrega de la joven y los consecuentes beneficios económicos de esta caída, y disfrutar a través del goce de Melibea. Entonces, hay un doble juego de espejos: Melibea ve un atroz futuro en la vieja alcahueta y esta rememora su juventud y sus placeres a través de los goces de la joven. Ambas, en direcciones opuestas, asumen como motor de sus acciones el individualismo y la satisfacción de los deseos personales, sentimientos que fluctúan a lo largo del texto. Otro ejemplo 
del temor y la impaciencia por el goce inmediato que se apoderan de Melibea se presenta cuando esta, ante la posibilidad de que Calisto ya no la desee, se arrepiente por haber dejado pasar un día antes de confesar a Celestina la pasión que la consume por Calisto:

¡O lastimada de mí! ¡O mal proueýda donzella! ¿E no me fuera mejor conceder su petición e demanda ayer Celestina, quando de parte de aquel señor, cuya vista me catiuó, me fue rogado, e contentarle a él e sanar a mí, que no venir por fuerça a descobrir mi llaga, quando no me sea agradecido, quando ya, desconfiando de mi buena respuesta, aya puesto sus ojos en amor de otra? ¡Quanta más ventaja touiera mi prometimiento rogado, que mi ofrecimiento forçoso! (x, 238).

Tal como señala María Rosa Lida, la impaciencia que expresa la joven por el día perdido «no es sino avaricia del goce, la reacción peculiar de Melibea a lo transitorio del tiempo" (414). Por otro lado, es importante recalcar el rol activo que desempeña Melibea en relación con la consumación de su relación pasional con Calisto. Melibea transgrede el prototípico papel de la heroína como la noble amada del relato caballeresco o sentimental, tradicionalmente relacionado con la pasividad e inocencia, pues es ella, y no Calisto, quien determina el espacio y tiempo de reunión con el amado. Asimismo, esta voluntad de acción es motivada por otro sentimiento convencionalmente asignado a los personajes masculinos: los celos, los cuales la empujan a la actuación inmediata y presurosa. Esta prisa toma un cariz fatídico cuando, por el apremio de seguir al amante mas allá de la muerte, Melibea se quita la vida frente al padre. Pero, como ya he subrayado, en su último monólogo, hay una marcada primacía del yo, pues la muerte del amante implica la suspensión de sus placeres. Como acertadamente indica María Embeita, Melibea «llora más la privación del deleite voluptuoso, que el fin del amado" (130)

Asimismo, Melibea subvierte otra de las expectativas de la sociedad patriarcal. La joven escucha escondida la conversación de los planes de sus padres por sujetarla al dominio de un esposo a través de los lazos del matrimonio. Melibea, quien recientemente ha descubierto los placeres de la sexualidad, se rebela contra los deseos de los padres y de la institución del matrimonio. El único interés que persigue Melibea, luego de sus encuentros secretos con Calisto, es la satisfacción inmediata de sus apetitos carnales. Nuevamente aparece la preocupación por el tiempo vinculado con la realización de los deseos personales: «No tengo otra lástima sino por el tiempo que perdí en gozarlo, de no conoscerlo, después que a mí se me conoscer. No quiero marido, no quiero ensuciar los ñudos del matrimonio, ni las maritales pisadas de ageno hombre» (xvI, 304). Calisto ha sido el medio a través del cual Melibea ha podido entender su propia 
interioridad; de este descubrimiento de su ser como sujeto terrenal con voluntad propia nace la transgresión a la hipocresía que supone el matrimonio. La exploración del yo encarna los modernos intereses cuyo foco es el ser individual.

Pleberio también muestra miedo ante la cercanía de la llegada de la muerte. Así como Calisto usa la imaginación y la memoria como armas de defensa contra el orden implacable del tiempo, Pleberio intenta usar la previsión contra el mismo enemigo. Por ello, discute con su esposa el posible matrimonio de su hija antes de que los sorprenda la muerte: "Alisa, amiga el tiempo, según me parece, se nos va, como dizen, entre las manos. Corren los días como agua de río. No hay cosa tan ligera para huyr como la vida. La muerte nos sigue e rodea, de la qual somos vezinos e hazia su vandera nos acostamos, según natura» (XVII, 301). Pero si Calisto intenta acelerar el tiempo, Pleberio desea que este le dé una tregua para ordenar su hacienda antes de morir. Pleberio vive, como los demás personajes, un tiempo íntimo, cuya corta duración es experimentada con particular intensidad, al igual que en el caso de Celestina, debido a la conciencia de su pronta muerte. En cualquier caso, ya sea por la prisa del amante o por la previsión del anciano, el intento de manipular los hilos del tiempo, como acontecer imperturbable frente a la arbitrariedad de las motivaciones humanas, es fallido y concluye solo en muerte y destrucción. Samuel Sánchez ha estudiado el cambio en la representación del impacto de la muerte en el discurso literario de la Edad Media y del Renacimiento. Para el crítico, las manifestaciones medievales de la pena por la muerte del ser querido se expresaban en forma colectiva, formulista y se concentraban en el muerto. En cambio, en la Edad Moderna el planctus es más secular; el centro del discurso se torna hacia el superviviente y su pena individual:

Whereas the universal and cultural aspects of grief define the Spanish literary response to death in Middle Ages, with the dawn of modernity the representation of grieving emerges as space for the interrogation of bereaved's identity by means of a personalized response to loss, a reaction that echoes the shift from the collective to the individual that characterizes modernity (148-9).

Habría que tener en cuenta que este cambio supone, entonces, una visión distinta acerca de la vida ultraterrena. El hombre medieval afronta la muerte con la confianza que le otorga la ideología cristiana de una vida mejor más allá de la existencia terrena. De ahí que la representación medieval de la muerte esté enfocada más en el muerto y su trascendencia póstuma. Sin embargo, hacia principios de la Edad Moderna, esta confianza se va minando; la pérdida de la fe en la trascendencia es bastante clara en el discurso final de Pleberio. La tristeza que abate al anciano 
frente a la muerte de su hija es inconsolable; el silencio y el abandono completo de la última escena representan el terrible pesimismo del que está teñida la obra. Pleberio se queda solo en este valle de lágrimas. Esta angustiante soledad no puede ser confortada ni con la esperanza de una mejor vida para su hija ni con la promesa de una reunión con esta en un espacio ultraterreno. Se niega, de esta manera, la concepción escatológica teocéntrica con la que se entendía el mundo, y se afirma más bien el anclaje del hombre al espacio y tiempo terrenales. De acuerdo con Gerli, el lamento del anciano «represents a rebellion against the ethos of religious and literary convention. It is an anguished plea for individualism opposed to the bogus security provide by uncritical conformity to literary traditions and Christian views» $(1976,73)$. Entonces, el lamento de Pleberio subraya el novedoso interés en la interioridad del yo, nuevo aspecto de la Edad Moderna. Cuando el anciano da la mala noticia a Alisa, dice: «nuestro gozo en el pozo; nuestro bien es todo perdido» (XXI, 336; el énfasis es mío). Así como el discurso de Melibea, ante la muerte de su amante, se concentra en las consecuencias que esta pérdida implica en los recientes placeres que ha descubierto la joven, el soliloquio de Pleberio subraya, sobre todo, las aflicciones que debe soportar el anciano, sin la asistencia de su heredera ni el consuelo cristiano. Asimismo, el recuento de los hechos más destacados de la vida del reciente difunto, Melibea, es sustituido por un balance de la vida del anciano: «He is more concerned with his own loneliness than with remembering the virtue and goodness of his daughter» (Corfis: 53). En ambos discursos elegíacos, el de Melibea y el de su padre, el foco de interés no es el muerto ni la esperanza en una vida futura, sino el dolor presente, en el mundo de hic y nunc, de quien debe sobrevivir la pérdida en la soledad absoluta: «¿Por qué me dexaste, quando yo te avía de dexar? ¿Por qué me dexaste penado? ¿Por qué me dexaste triste y solo in hac lacrimarum valle?» (xxI, 343).

Una de las cualidades especiales de La Celestina es la caracterización del ambiente de tránsito que experimenta la sociedad en el otoño de la Edad Media y en su despertar hacia el Renacimiento. A través del análisis del planctus de Pleberio hemos podido comprobar un elemento novedoso: el germen de la duda en relación a la esperanza en la salvación y la posibilidad consoladora en una vida ulterior. Celestina es el personaje que más parece creer en la existencia del Mal, encarnado por el demonio al cual invoca en sus conjuros para asegurar el éxito de su empresa, y, por tanto, del Bien. Sin embargo, también el miedo y la incertidumbre asaltan a la alcahueta, quien ya no confía enteramente en fuerzas sobrenaturales, sino más bien en los poderes de la voluntad del hombre y de sus inclinaciones internas. La oscilación entre la creencia medieval en poderes ultraterrenos y la nueva mentalidad renacentista que está emergiendo se representa claramente en la escena de los conjuros de Celestina seguido por el capítulo en que hallamos a la anciana sola caminando por las calles 
haciendo un balance sobre los próximos movimientos de sus proyectos. Cuando Celestina lanza su famoso conjuro para lograr la rendición de Melibea, Elisa y Pármeno están en la casa. Celestina requiere la confianza de ambos personajes: necesita los «trabajos» de Elisa para sobrevivir y la fidelidad de Pármeno para ganar el favor de Calisto. Entonces, la magia es otra herramienta, junto a su deslumbrante uso de la retórica, que emplea la alcahueta: el hechizo, que respeta las características tradicionales de un conjuro típico, es una especie de representación de Celestina, tanto para persuadir a la pareja que la escucha como para autoconvencerse sobre sus poderes sobrehumanos. Sin embargo, Celestina culmina su maleficio con una frase en la que subraya la seguridad en su propio poder más que en la del "triste Plutón»; "assi confiando en mi mucho poder, me parto para allá con mi hilado: donde creo te lleuo ya embuelto» (III, 147, el énfasis es mío). Además, justo después de la escena del maleficio, Celestina se lanza sola a las calles de la ciudad y maneja un discurso completamente distinto. En la intimidad de esta soledad, Celestina se detiene a contrapesar los beneficios que la empresa que Calisto le ha delegado le puede traer. Es decir que la confianza en cualquier fuerza trascendente se desbarata completamente cuando Celestina pone en tela de juicio la seguridad que los poderes demoniacos parecían ofrecerle en la escena justamente anterior:

Agora que voy sola, quiero mirar bien lo que Sempronio ha temido deste mi camino: porque aquellas cosas que bien no son pensadas: avnque algunas vezes ayan buen fin, comunmente crian desuariados efetos: assi que la mucha especulacion nunca carece de buen fruto. Que avnque yo he dissimulado con el, podria ser que, si me sintiessen en estos passos de parte de Melibea, que no pagasse con pena que menor fuesse que la vida, o muy amenguada quedasse: quando matar no me quisiessen, manteandome o azotandome cruelmente. Pues amargas cient monedas serian estas. ay cuytada de mi! en que lazo me he metido: que por me mostrar solicita e esforzada pongo mi persona al tablero: que fare, cuytada, mezquina de mi: que ni el salir afuera es prouechoso: ni la perseuerancia carece de peligro. pues yre / o tornarme he? o dubdosa e dura perplexidad: no se qual escoja por más sano (IV, 149, el énfasis es mío).

En este soliloquio, es fácil identificar que la escena de la magia ha sido un mero artificio: "yo he disimulado". La magia es solo una careta por encima de la cual se erige el uso de la razón. Ante la «dura perplexidad» que asalta a Celestina, ella se inclina por la especulación en el aquí y ahora. Reflexiona metódicamente, contrapone argumentos y asume una 
decisión basada en una ilación de razonamientos. Somos testigos del desplome de una explicación sobrenatural del mundo, discurso substituido por una visión pragmático-racional. De esta manera, el enfoque de un espacio-tiempo trascendental sufre fisuras que suponen un cambio radical de pensamiento.

En conclusión, como vemos, el tiempo en La Celestina se vive intensamente, "como tal sin falsas decoraciones ni escapistas y complejas abstracciones; importa el tiempo, escuetamente, y la vida del hombre en ese tiempo" (Rodríguez-Puertolas 151). Hemos podido comprobar, a través de una lectura atenta de la obra y del análisis de la interioridad de los personajes, el complejo funcionamiento del tiempo en La Celestina. Este es percibido de maneras disímiles de acuerdo a la íntima conciencia subjetiva de cada personaje. Así, si, por una parte, estos poseen una clara conciencia temporal que los apremia constantemente y los empuja a asumir decisiones en las que priman los nuevos principios del individualismo, la autodeterminación y el egoísmo, por otro lado, esta conciencia temporal se representa en la obra a través de expresiones subjetivas e íntimas, formas diversas de comprender y vivir un tiempo que ha perdido su estatismo y universalidad para convertirse en una categoría más flexible y personal, es decir, más humana. 


\section{Bibliografía}

AlCalÁ, Ángel. "Rojas y el Neoepicureísmo. Notas sobre la intención de La Celestina y el silencio posterior de su autor'. 'La Celestina' y su contorno social: Actas del I Congreso Internacional sobre La Celestina / patrocinado por el Ministerio de Educación y Ciencia... [et al.] ; dirección, Manuel Criado de Val. Barcelona: Hispan-Borrás Ediciones, 1977, pp. 35-50.

Alcalá Galán, Mercedes. "Voluntad de poder en Celestina». Celestinesca 20 (1996): 37-55.

Asencio, Manuel T. "El tiempo en La Celestina». Hispanic Review 20.1 (1952): 28-43. JSTOR. Web. 13 Feb. 2010.

Ayllón, Cándido. La visión pesimista de "La Celestina». México: Ediciones de Andrea, 1965.

Berndt, Erna Ruth. Amor, muerte y fortuna en "La Celestina». Madrid: Editorial Gredos, 1963.

Burke, James F. "Sympathy and Antipathy in La Celestina». Comparative Literature 39.1 (1987): 19-27.

Corfis, Ivy A. "Imagery of Love and Death in Pleberio's Lament». Celestinesca 25 (2001): 47-56.

Embeita, María. "La Celestina, obra del Renacimiento». 'La Celestina' y su contorno social: Actas del I Congreso Internacional sobre La Celestina / patrocinado por el Ministerio de Educación y Ciencia... [et al.] ; dirección, Manuel Criado de Val. Barcelona: Hispam-Borrás Ediciones, 1977, pp. 125-134.

Fernández Rivera, Enrique. "El reloj, la hora, y la economía en La Celestina». Celestinesca 34 (2010): 31-42.

Gerli, E. Michael. "The Ideology of Space in Celestina». Celestinesca 21 (1997): 65-77.

-. "Pleberio's Lament and Two Literary Topoi: Expositor and Planctus». Romanische Forschungen 88 (1976): 67-74.

Gilman, Stephen. "El tiempo y el género literario en la Celestina. Revista de Filología hispánica 7 (1945): 147-159.

-. The Art of "La Celestina». Madison: University of Wisconsin Press, 1956.

- The Spain of Fernando de Rojas; The Intellectual and Social Landscape of "La Celestina». Princeton: Princeton University Press, 1972.

GurzA, Esperanza. Lectura existencialista de "La Celestina». Madrid: Editorial Gredos, 1977.

Handy, Otis. "La desfloración psicológica y retórica de Melibea». Estudios sobre "La Celestina». Ed. Santiago López-Ríos. Madrid: Ediciones Istmo, 2001, pp. 381-393. 
Herrero, Javier. "Celestina: The Aging Prostitute as Witch». Aging in Literature. Eds. Laurel Porter y Laurence M. Porter. Michigan State University: Michigan, 1984, pp. 31-49.

LIDA De Malkiel, María Rosa. La originalidad artística de "La Celestina». $2^{\mathrm{a}}$ ed. Buenos Aires: Editorial Universitaria de Buenos Aires, 1970.

Mencé-Caster, Corinne. "Temporalité et éthique dans La Celestina». Celestinesca 32 (2008): 209-229.

Palafox, Eloísa. "Celestina y su retórica de seducción: Comida, vino y amor en el texto de la Tragicomedia». Revista Canadiense de Estudios Hispánicos 32.1 (2007 Fall): 71-88.

Rodríguez-PuÉRTOLAS, Julio. "La Celestina o la negación de la negación». Literatura, Historia, Alienación. Barcelona: Editorial Labor, 1976, pp. 147-172.

- De la Edad Media a la edad conflictiva; estudios de Literatura Española. Madrid: Gredos, 1972.

RojAS, Fernando de. La Celestina. 14ª ed. Edición de Dorothy S. Severin. Madrid: Cátedra, 2004.

Russell, Peter. "La magia, tema integral de La Celestina». Estudios sobre la "Celestina». Ed. Santiago López-Ríos. Madrid: Ediciones Istmo, 2001, pp. 281-311.

SÁnCHez y SÁnchez, Samuel. «Death Gets Personal: Inventing Early Modern Grief in 15th Century Spain». Celestinesca 34 (2010): 145-178.

Severin, Dorothy S. Memory in "La Celestina". London: Tamesis, 1970.

Snow, Joseph T. "Alisa, Melibea, Celestina y la magia». Estudios sobre la "Celestina». Ed. Santiago López-Ríos. Madrid: Ediciones Istmo, 2001, pp. 312-324.

WeST, Geoffrey. "The Unseemliness of Calisto's Toothache». Celestinesca 3.1 (1979): 3-10.

YGLeSIAS, Yolanda. "Rompiendo las cadenas: el libre albedrío en los personajes de La Celestina». Celestinesca 34 (2010): 57-74. 


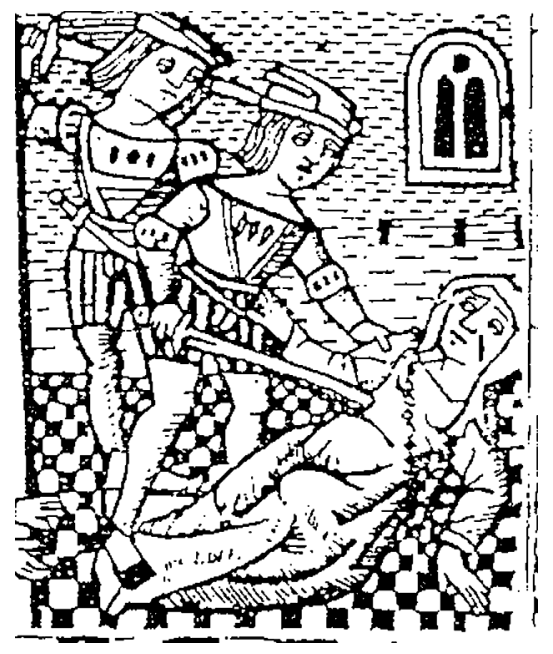


Galarreta-Aima, Diana, «El tiempo en La Celestina: el deseo, el placer y el egoísmo como motivos de interpretación de la obra", Celestinesca 35 (2011), pp. 43-66.

\section{RESUMEN}

El estudio de la conciencia temporal de los personajes de La Celestina nos permite comprender mejor los cambios que se están operando en la sociedad de finales de la Edad Media. A la vez, el análisis de este preciso y especial periodo histórico nos puede dar ciertas claves para comprender el modo de pensar y actuar de los personajes. La propuesta de este artículo es realizar un análisis en dos direcciones, aparentemente opuestas, pero complementarias: por un lado, el tiempo como factor que constriñe las pasiones de los personajes y que, por tanto, mueve sus acciones en una lucha implacable contra este, y, por otro, la creación de una conciencia íntima y relativa del tiempo de acuerdo a las características personales de cada uno de los personajes.

palabras ClaVE: Celestina, tiempo, conciencia, pasiones, memoria, imaginación.

\section{ABSTRACT}

The study of the temporal consciousness of La Celestina's characters allow us to understand better the ongoing changes of the society at the end of the Middle Ages. At the same time, the analysis of this precise and special historic period provides us certain keys to comprehend the way of thinking and acting of the characters. The proposal of this article is doing an analysis in two directions, apparently conflicting, but complementary: on one hand, time as a factor that constrains the characters' passions so that it moves their actions in an implacable battle against it, and, on the other hand, the creation of an personal and relative consciousness of time according to the personal features of each one of the characters.

KEY WORDS: Celestina, time, conscience, passion, memory, imagination. 